\title{
Editorial: Advancing a Cross Boundary Social Science of Trust in Natural Resource Management
}

\author{
Kristina M. Slagle ${ }^{1 * t}$, Dara M. Wald ${ }^{2 \dagger}$ and Joseph A. Hamm ${ }^{3+}$ \\ ${ }^{1}$ School of Environment and Natural Resources, The Ohio State University, Columbus, OH, United States, ${ }^{2}$ Greenlee School of \\ Journalism and Communication, lowa State University, Ames, IA, United States, ${ }^{3}$ School of Criminal Justice and Environmental \\ Science and Policy Program, Michigan State University, East Lansing, MI, United States
}

Keywords: trust, natural resouces management, communication, collaboration, vulnerability

Editorial on the Research Topic

Advancing a Cross Boundary Social Science of Trust in Natural Resource Management

\section{INTRODUCTION}

Managing natural resources requires coordinating across groups and individuals who often have conflicting, if not competing, interests and needs. As natural resource management (NRM) models shift from top-down to more collaborative approaches, understanding how trust among individuals and groups forms, is negotiated, and can deteriorate has become critical and a growing body of literature has much to say about the nature and dynamics of trust in this context. In general, trust influences the interpretation of information, increases support for management actions, and facilitates collective action (Vaske et al., 2007; Ostrom, 2010; Winter and Cvetkovich, 2010; Lachapelle and McCool, 2012; Brewer and Ley, 2013) but becomes especially critical under conditions of uncertainty, complexity, and controversy (Stern, 2008; Winter and Cvetkovich, 2010).

Despite the clear refrain that "trust matters," this growing body of literature has yet to be effectively Kristina M. Slagle Slagle.44@osu.edu

${ }^{\dagger}$ These authors have contributed equally to this work

Specialty section:

This article was submitted to Science and Environmental Communication,

a section of the journal Frontiers in Communication

Received: 06 April 2021 Accepted: 16 April 2021

Published: 30 April 2021

Citation: integrated in a way that enables it to optimally impact the science and practice of NRM. Instead-and consistent with the wider scholarship of trust (see Hamm et al., 2016) - this work is typically conducted in relatively disconnected silos focused on issues like climate change, water quantity or quality, species ecology, and rangeland management through any number of more or less distinct disciplinary lenses. Thus, although we know much about contextualized trust, less has been done to look across these efforts to identify the core elements of the construct that are consistent and those that are more likely to change. The development of this cross-boundary social science of trust is important because of its potential to integrate existing research but also as a meaningful starting point for new research in un(der)-explored contexts.

The current special issue advances the development of this cross-boundary perspective through five articles which integrate thinking across traditional disciplinary or contextual boundaries to explore the nature and dynamics of trust. Toman et al. open with a Perspective Article that explores the practical importance of trust for natural resource management efforts. Emborg et al. then harken back to a classic trust article by Lewicki et al. (1998) in a Conceptual Analysis of the interplay-and especially the potential for the coexistence-of trust and distrust. The special issue then presents two Original Research Articles that take very different approaches to exploring the likely antecedents of trust. Ford et al. employ a quantitative meta-analytic approach to synthesizing the existing research that explores the predictors of trust among a variety of stakeholders across NRM contexts. Hamm et al. report on a qualitative inquiry that evaluates the potential for trustworthiness and motivation as distinct drivers of trust in the sub-Saharan community water management context. Finally, a Hypothesis and Theory 
Article by Rapp synthesizes much of this thinking to provide concrete steps for future research, particularly around explicit instances of collaboration.

In the current editorial, we review the five pieces using four questions that have significant potential for elucidating the essential elements of any trusting relationship. To this end, we provide a brief review of each question and contextualize the five articles against them, highlighting the contribution of each article to a crossboundary understanding of trust that both advances the literature and provides concrete guidance for practitioners.

\section{QUESTION 1: WHO OR WHAT IS TRUSTING (THE TRUSTOR) AND WHO OR WHAT IS BEING TRUSTED (THE TRUSTEE)?}

Foundational to understanding any trust relationship is the identification of the actors involved. Although generalized (e.g., Rothstein and Stolle, 2008) and dyadic conceptualizations of trust are common (e.g., Korsgaard et al., 2015), trust is most often understood as a psychological state within one individual (the trustor) as directed to a specific other (the trustee) that the trustor perceives to have some level of control over the likelihood or severity of harm that the trustor may experience (e.g., Mayer et al., 1995). The NRM context is typified by a wide variety of individuals and groups that may serve as trustors or trustees, depending upon the situational realities of a given place and time (see Emborg et al.). There are numerous ways in which NRM stakeholders impact-or appear to impact-each other (see Hamm 2017). For example, powerful actors in decision-making processes can deny other actors' agenda or use their influence to capture the outcome (Bixler et al., 2016; Dietsch et al., 2021). Trust among actors with a vested interest or stake in the outcome facilitates their coordination in the face of this vulnerability. Toman et al. organize these actors into three groups: NRM agencies, the individuals employed by those agencies, and everyone else with some kind of stake in management decisions (e. g., local residents, property owners, and private businesses). Implicit in the contrast between the first and second groups is the importance of distinguishing agencies from the individuals that represent them (see also Ford et al.). Research in the NRM context suggests that the trustworthiness of agencies and their staff are related but not perfectly so (e.g., Sharp and Curtis, 2014). Emborg et al. further distinguish between trust in agencies and agency staff to help explain how individuals may be more or less willing to accept vulnerability posed by individual staff as compared to the organization they represent. Ford et al. add to this a second important distinction for sorting out trust relationships and argue that trust may exist in vertical (between actors with asymmetric control over each other's potential harm) and horizontal relationships (among peers). In their analysis, they find that both distinctions matter but only for the impact of fairness on trust which appears to be stronger when the trustee is a person (as compared to an organization) and when the relationship is vertical (as compared to horizontal). Rapp similarly argues that, practitioners guiding collaborative processes should maintain a clear view of where actors sit within the collaborative network (e.g., central or peripheral; empowered or disempowered), as addressing this can impact the overall success of these collaborations.

\section{QUESTION 2: WHAT IS THE NATURE OF THE INTERDEPENDENCE IN THE RELATIONSHIP BETWEEN THE TRUSTOR AND TRUSTEE?}

Research increasingly positions interdependence as a critical precondition such that, in order for trust to be relevant, the trustor must have 1) some level of real or perceived dependence on the trustee that they consider to be important, and 2) some level of uncertainty about the extent to which that dependence is protected (e.g., PytlikZillig and Kimbrough, 2016). In most research, this interdependence and uncertainty are conceptualized as vulnerability such that the trustor must have some potential for experiencing valued harm rooted in the deliberate behavior of the trustee. Hamm et al., position this vulnerability as a key element of all interactions between actors such that all trustors exist in a state of uncertainty regarding their potential for injury as a result of the trustee's deliberate action (or inaction). Emborg et al. address the variety of interdependencies, even within the same trustor/trustee dyad, in their discussion of relationship domains. They argue the variety of interdependencies (coupled with the variety in levels and bases of trust) contributes to the potential for multiplex relationships in which a given trustor may feel a strong level of trust in one domain while being much less trusting in another. The diversity of actors, levels, and domains in NRM creates a considerable variety of potentially salient vulnerabilities that range from rude treatment in horizontal relationships between individuals to landowners' loss of autonomy in service of state agency action driven by federal laws like the Endangered Species Act. Understanding the vulnerabilities that are valued in any given NRM relationship, and how they vary across situations and contexts, is critical and research has started to shed some light on these concerns at both the macro (e.g., Thiault et al., 2020) and micro level (e.g., Winter and Palucki, 1999; Walpole and Wilson, 2021). Hamm et al. add to the body of work addressing the micro level via interviews in southwestern Uganda that highlighted the potential for injury when water management committees mismanage community funds.

\section{QUESTION 3: WHY WOULD THE TRUSTOR BE WILLING TO ACCEPT THEIR VULNERABILITY TO THE DELIBERATE ACTIONS OF THE TRUSTEE?}

When discussing the reasons why a trustor would trust, most current trust research focuses on elements of the relationship itself (however, for a thorough exploration of the modern role of dispositional trust, see Rapp). Ford et al. provide a comprehensive review of the antecedents in the NRM literature and highlight reputation, communication, shared norms and values, cooperation and support, past behavior, satisfaction with services provided, and fairness. In an analysis that did not include fairness because of issues with multicollinearity, reputation and cooperation/support had the strongest impact on trust while service quality in particular was associated with a much smaller effect. Hamm et al., applied a slightly different approach to understanding antecedents and focused on three characteristics of the trustee that make them appear worthy of trust. Applying the MDS model (Mayer et al., 1995), 
the authors inductively coded qualitative interviews for the presence of ability, benevolence, and integrity as reasons for trust. Following research suggesting that trustors may choose to collaborate with trustees in the pursuit of shared environmental goals, even in the presence of distrust (Wald et al., 2019; see also; Li, 2015; van der Werff et al., 2019), the authors also coded references to motivation, arguing that a need for a relationship may create a pressure toward trust that is distinct from assessments of trustworthiness. Emborg et al. suggests that when trustees convey a need to repair or build trust, it is because they have recognized evidence of distrust. Toman et al. follow on these arguments and provide concrete guidance for NRM practitioners. Specifically, they argue that practitioners should work to facilitate meaningful interactions where their trustworthiness can be demonstrated, to identify salient vulnerabilities and demonstrate specific trustworthiness with regard to them, and to capitalize on the motivation that may arise from shared interests in ensuring that something gets done.

\section{QUESTION 4: SO WHAT?}

Research across NRM contexts has long addressed why trust matters, suggesting that it increases cooperation and compliance (e.g., Stern, 2008), support for management action (e.g., Schroeder and Fulton, 2017), and facilitates collaborative governance (e.g., Payton et al., 2005). All five articles in the special issue echo these benefits of trust and especially focus on its connection to collaborative management. What is perhaps more novel here, however, is discussion of the potential for a positive role for distrust (Emborg et al.). As argued throughout this editorial and the special issue, natural resource management involves a variety of stakeholders, all of which have important relationships with each other which must be negotiated in light of different and even competing interests. This complexity increases the likelihood of distrust, which may actually provide an important motivation for bringing stakeholders together (e.g., Emborg, et al., Smith et al., 2013; Parkins et al., 2017) in a way that could permit building trust among them (see also Toman et al.). Thus, although some kind of trust is likely necessary for effective natural resource management, distrust between some actors for some vulnerabilities may have an important role to play, and deserves increased attention in the NRM literature.

\section{THINKING FORWARD}

The benefits of trust and the impediments of distrust will remain important avenues for research in NRM contexts moving forward. Indeed, the articles in this special issue suggest this research will likely become more nuanced over time, and rightly so. Moving toward a multidimensional view of trust, will require a more complete understanding of the diversity of trust relationships, including vertical, horizontal or asymmetrical, that may occur in NRM contexts. While this complexity may increase the likelihood of distrust and have a variety of interdependencies, it also opens the door to new pathways for stakeholders to build or repair trust.

By viewing vulnerability as a key element of all interactions between actors, this special issue highlights the need for greater understanding of how these vulnerabilities are valued across NRM contexts and how they emerge and inform NRM outcomes. For example, how do different relationship types (e.g., asymmetrical, horizontal, vertical) between and among actors intersect with different vulnerabilities or motivations? What are the organizational, social, and individual barriers to accepting vulnerability, particularly among scientists, decision makers, and environmental managers? Previous research suggests that environmental managers can be unwilling to accept collaborative decisions in NRM contexts because doing so could make them vulnerable to professional censure due to a perceived lack of objectivity or integrity (Orth and Cheng, 2018). But if vulnerability is a necessary part of trust, then environmental managers' unwillingness to accept these potential vulnerabilities could create distrust or prevent trust in collaborative NRM contexts.

In addition, the complexity of trust highlighted here suggests a need to widen our lens around who counts as a stakeholder in NRM contexts, and under what societal conditions these interactions take place. Throughout the articles in this issue, and within this editorial, scientists and environmental managers are not explicitly defined as stakeholders, and thus, are often placed outside of conversations around trust in NRM contexts. This is an occupational hazard for scientists, and here we argue that it is a mistake, especially for those of us focused on the environment.

Trust is often described as a shortcut that the public uses to interpret and evaluate new or complex scientific information and competing knowledge claims (Pornpitakpan, 2004; Vraga et al., 2018). Research drawn from national surveys suggest that public perceptions of scientific trustworthiness are strongly associated with lay approval for scientific influence on environmental policies and regulation (O'Brien, 2013; Gauchat et al., 2017; Safford et al., 2020). While confidence in scientists is high among the American public, political affiliation heavily skews trust in environmental scientists (Pew Research Center, 2019), suggesting that the scientific community could benefit from a deeper understanding of trust, particularly if broad political polarization continues to exacerbate this problem (Achen and Bartels, 2017). Understanding trust, how it emerges, and how to rebuild it will serve environmental scientists into the future-both in solving the problems that spur their research, and in ensuring that the potential benefits of scientific research contribute to public wellbeing and improve NRM for all.

\section{AUTHOR CONTRIBUTIONS}

All three editors (KS, DW, and $\mathrm{JH}$ ) contributed equally to the special issue and this editorial. The authors of this editorial are listed by rank to advantage early career researchers.

\section{ACKNOWLEDGMENTS}

The editors are greatly indebted to the authors and reviewers who made this special issue possible. The editors are also grateful for the guidance of Tarla Rai Peterson, who helped move this from a conversation to a research topic. 


\section{REFERENCES}

Achen, C. H., and Bartels, L. M. (2017). Democracy for Realists: Why Elections Do Not Produce Responsive Government. Vol. 4. Princeton, NJ: Princeton University Press.

Bixler, R. P., Wald, D. M., Ogden, L. A., Leong, K. M., Johnston, E. W., and Romolini, M. (2016). Network Governance for Large-Scale Natural Resource Conservation and the Challenge of Capture. Front. Ecol. Environ. 14 (3), 165-171. doi:10.1002/fee.1252

Brewer, P. R., and Ley, B. L. (2013). Whose Science Do You Believe? Explaining Trust in Sources of Scientific Information about the Environment. Sci. Commun. 35 (1), 115-137. doi:10.1177/1075547012441691

Dietsch, A., Wald, D. M., Tully, B., and Stern, M. (2021). Trust, Identity, and Power: TIPs for Success when Engaging Conservation Partners. Conservation Sci. Pract.. In Press. doi:10.1111/csp2.421

Gauchat, G., O'Brien, T., and Mirosa, O. (2017). The Legitimacy of Environmental Scientists in the Public Sphere. Climatic Change 143 (3), 297-306. doi:10.1007/ s10584-017-2015-z

Hamm, J. A. (2017). Trust, Trustworthiness, and Motivation in the Natural Resource Management Context. Soc. Nat. Resour. 30 (8), 919-933. doi:10.1080/08941920.2016.1273419

Hamm, J. A., Lee, J., Trinkner, Rick., Wingrove, T., Leben, S., and Breuer, C. (2016). "On the Cross-Domain Scholarship of Trust in the Institutional Context," in Interdisciplinary Perspectives on Trust. Editors E. Shockley, M. Tess, S. Neal, L. M. PytlikZillig, and B. H. Bornstein (Cham: Springer International Publishing), 131-156. doi:10.1007/978-3-319-22261-5_8

Korsgaard, M. A., Brower, H. H., and Lester, S. W. (2015). It Isn't Always Mutual. J. Manage. 41 (1), 47-70. doi:10.1177/0149206314547521

Lachapelle, P. R., and McCool, S. F. (2012). The Role of Trust in Community Wildland Fire Protection Planning. Soc. Nat. Resour. 25 (4), 321-335. doi:10.1080/08941920.2011.569855

Lewicki, R. J., McAllister, D. J., and Bies, R. J. (1998). Trust and Distrust: New Relationships and Realities. Acad. Manage. Rev. 23 (3), 438-458. doi:10.2307/ 259288

Li, P. P. (2015). "Trust as a Leap of Hope for Transaction Value: A Two-Way Street above and beyond Trust Propensity and Expected Trustworthiness," in Motivating Cooperation and Compliance with Authority: The Role of Institutional Trust. Editors B. H. Bornstein and Alan. J. Tomkins (Cham: Springer International Publishing), 37-53. doi:10.1007/978-3-319-16151-8_3

Mayer, R. C., James, H., Schoorman, F. D., and Schoorman, J. H. (1995). An Integrative Model of Organizational Trust. Acad. Manage. Rev. 20 (3), 709-734. doi: $10.2307 / 258792$

O'Brien, T. L. (2013). Education and Support for Scientists and Elected Officials in Public Policy Decisions. Sci. Public Pol. 40 (3), 340-353. doi:10.1093/scipol/ $\operatorname{scs} 112$

Orth, P. B., and Cheng, A. S. (2018). "Who's in Charge? the Role of Power in Collaborative Governance and Forest Management. Humboldt J. Soc. Relations 40, 191-210.

Ostrom, E. (2010). Analyzing Collective Action. Agric. Econ. 41 (November), 155-166. doi:10.1111/j.1574-0862.2010.00497.x

Parkins, J. R., Beckley, T., Comeau, L., Stedman, R. C., Rollins, C. L., and Kessler, A. (2017). Can Distrust Enhance Public Engagement? Insights from a National Survey on Energy Issues in Canada. Soc. Nat. Resour. 30 (8), 934-948. doi:10.1080/08941920.2017.1283076

Payton, M. A., Fulton, D. C., and Anderson, D. H. (2005). Influence of Place Attachment and Trust on Civic Action: A Study at Sherburne National Wildlife Refuge. Soc. Nat. Resour. 18, 511-528. doi:10.1080/08941920590947940

Pew Research Center (2019). Trust and Mistrust in Americans' Views of Scientific Experts. Available at: https://www.pewresearch.org/science/2019/08/02/trust-andmistrust-in-americans-views-of-scientific-experts/ (Accessed October 1, 2020).
Pornpitakpan, C. (2004). The Persuasiveness of Source Credibility: A Critical Review of Five Decades' Evidence. J. Appl. Soc. Pyschol 34 (2), 243-281. doi:10. 1111/j.1559-1816.2004.tb02547.x

PytlikZillig, L. M., and Kimbrough, C. D. (2016). Consensus on Conceptualizations and Definitions of Trust: Are We There yet?. in Interdisciplinary Perspectives on Trust. Editors E. Shockley, T. Neal, L. PytlikZillig, and B. Bornstein (Cham: Springer).

Rothstein, B., and Stolle, D. (2008). The State and Social Capital: An Institutional Theory of Generalized Trust. Comp. Polit. 40 (4), 441-459. doi:10.5129/ $001041508 \times 12911362383354$

Safford, T. G., Whitmore, E. H., and Hamilton, L. C. (2020). Questioning Scientific Practice: Linking Beliefs about Scientists, Science Agencies, and Climate Change. Environ. Sociol. 6 (2), 194-206. doi:10.1080/23251042.2019.1696008

Schroeder, S. A., and Fulton, D. C. (2017). Voice, Perceived Fairness, Agency Trust, and Acceptance of Management Decisions Among Minnesota Anglers. Soc. Nat. Resour. 30 (5), 569-584. doi:10.1080/08941920.2016.1238987

Sharp, E., and Curtis, A. (2014). Can NRM Agencies Rely on Capable and Effective Staff to Build Trust in the Agency? Australasian J. Environ. Manage. 21 (3), 268-280. doi:10.1080/14486563.2014.881306

Smith, J. W., Leahy, J. E., Anderson, D. H., and Davenport, M. A. (2013). Community/Agency Trust and Public Involvement in Resource Planning. Soc. Nat. Resour. 26 (4), 452-471. doi:10.1080/08941920.2012.678465

Stern, M. J. (2008). Coercion, Voluntary Compliance and Protest: The Role of Trust and Legitimacy in Combating Local Opposition to Protected Areas. Envir. Conserv. 35, 200-210. doi:10.1017/s037689290800502x

Thiault, L., Gelcich, S., Marshall, N., Marshall, P., Chlous, F., and Claudet, J. (2020). "Operationalizing Vulnerability for Social-Ecological Integration in Conservation and Natural Resource Management. Conservation Lett. 13 (1). doi:10.1111/conl.12677

van der Werff, L., Legood, A., Buckley, F., Weibel, A., and de Cremer, D. (2019). Trust Motivation: The Self-Regulatory Processes Underlying Trust Decisions. Organizational Psychol. Rev. 9 (2-3), 99-123.

Vaske, J. J., Absher, J. D., and Bright, A. D. (2007). Salient Value Similarity, Social Trust and Attitudes toward Wildland Fire Management Strategies. Hum. Ecol. Rev. 14 (2), 223-232.

Vraga, E., Myers, T., Kotcher, J., Beall, L., and Maibach, E. (2018). Scientific Risk Communication about Controversial Issues Influences Public Perceptions of Scientists' Political Orientations and Credibility. R. Soc. Open Sci. 5 (2), 170505. doi:10.1098/rsos.170505

Wald, D. M., Nelson, K. A., Gawel, A. M., and Rogers, H. S. (2019). The Role of Trust in Public Attitudes toward Invasive Species Management on Guam: A Case Study. J. Environ. Manage. 229 (January), 133-144. doi:10.1016/j.jenvman.2018.06.047

Walpole, H. D., and Wilson, R. S. (2021). Extending a Broadly Applicable Measure of Risk Perception: The Case for Susceptibility. J. Risk Res. 24 (2), 135-147. doi:10.1080/13669877.2020.1749874

Winter, P. L., and Cvetkovich, G. T. (2010). Trust Mediates Conservation-Related Behaviors. Ecopsychology 2 (4), 211-219. doi:10.1089/eco.2010.0046

Winter, P. L., Palucki, L. J., and Burkhardt, R. L. (1999). Anticipated Responses to a Fee Program: The Key Is Trust. J. Leis. Res. 31 (3), 207-226. doi:10.1080/ 00222216.1999 .11949864

Conflict of Interest: The authors declare that the research was conducted in the absence of any commercial or financial relationships that could be construed as a potential conflict of interest.

Copyright $(2) 2021$ Slagle, Wald and Hamm. This is an open-access article distributed under the terms of the Creative Commons Attribution License (CC BY). The use, distribution or reproduction in other forums is permitted, provided the original author(s) and the copyright owner(s) are credited and that the original publication in this journal is cited, in accordance with accepted academic practice. No use, distribution or reproduction is permitted which does not comply with these terms. 